\title{
Temperatura de superfície e uso e cobertura do solo em municípios da região metropolitana de Belém/PA
}

As formas de uso e cobertura do solo desordenadas resultam na intensa impermeabilização das cidades, além de provocar a intensificação das ilhas de calor. $\mathrm{O}$ geoprocessamento tem sido uma ferramenta primordial, com grandes avanços, para as etapas de levantamento e processamento de informações relacionadas a questões ambientais. 0 estudo tem como objetivo avaliar as alterações de temperatura de superfície terrestre e no uso e cobertura do solo nos anos de 2001, 2008 e 2018 nos municípios de Belém e Ananindeua/PA, com uso de imagens dos satélites Landsat 5 e 8. Para as análises foram confeccionados mapas de Uso e Cobertura do solo e de Temperatura da Superfície Terrestre (TST). O tratamento e análise dos dados das imagens em todas as etapas foram realizados pelo software QGis 2.18. Constatou-se que não ocorreu variação classe de vegetação densa dos anos de 2001 a 2008 , havendo mudança significativa apenas no ano de 2018. Em relação a classe vegetação secundaria, observou-se que de 2001 a 2018 ocorreu uma perda de $44 \%$ dessa classe. Quanto a classe área antropizada, observou-se um aumento de $62 \%$ nos anos avaliados, foi a classe onde ocorreu a maior evolução de área. Para a temperatura dos municípios em estudo observou-se que na região norte no ano de 2001 , a temperatura era de no máximo $23^{\circ} \mathrm{C}$, no entanto, no ano de 2018 apresentou valores superiores, variando de $20^{\circ} \mathrm{C}$ a $26^{\circ} \mathrm{C}$. De acordo com os resultados, o aumento da urbanização nesses municípios metropolitanos vem se intensificando com o passar dos anos e invadido novas áreas, o que ocasiona um desequilíbrio ambiental cada vez maior nessas regiões. Assim, as ferramentas de geoprocessamento se mostram excelentes para o diagnóstico e a tomada de decisão no monitoramento da qualidade ambiental e do planejamento urbano da região.

Palavras-chave: Geoprocessamento; Temperatura; Uso do Solo; Belém; Qualidade Ambiental.

\section{Surface temperature and land use and coverage in municipalities in the metropolitan region of Belém/PA}

\begin{abstract}
The disordered forms of land use and cover result in the intense waterproofing of cities, in addition to causing the intensification of heat islands. Geoprocessing has been a primary tool, with great advances, for the stages of gathering and processing information related to environmental issues. The study aims to assess changes in the temperature of the Earth's surface and in land use and cover in 2001, 2008 and 2018 in the municipalities of Belém and Ananindeua/PA, using images from the Landsat 5 and 8 satellites. For the analyzes were made maps of Land Use and Coverage and Earth Surface Temperature (EST). The treatment and analysis of image data at all stages were performed using the QGis 2.18 software. It was found that there was no variation in the class of dense vegetation from 2001 to 2008 , with a significant change only in 2018. In relation to the secondary vegetation class, it was observed that from 2001 to 2018 there was a loss of $44 \%$ of this class. As for the anthropized area class, there was an increase of $62 \%$ in the years evaluated, it was the class where the greatest area evolution occurred. For there was a loss of $44 \%$ of this class. As for the anthropized area class, there was an increase of $62 \%$ in the years evaluated, it was the class where the greatest area evolution occurred. For
the temperature of the municipalities under study, it was observed that in the northern region in 2001 , the temperature was at most $23^{\circ} \mathrm{C}$, however, in 2018 it presented higher values, ranging from $20^{\circ} \mathrm{C}$ to $26^{\circ} \mathrm{C}$. According to the results, the increase in urbanization in these metropolitan municipalities has been intensifying over the years and has invaded new areas, which causes an increasing environmental imbalance in these regions. Thus, the geoprocessing tools are excellent for diagnosis and decision making in monitoring the environmental quality and urban planning of the region.
\end{abstract}

Keywords: Geoprocessing; Temperature; Land Use; Belém; Environmental Quality.

Topic: Geodésia, Cartografia e Sensoriamento Remoto

Reviewed anonymously in the process of blind peer.

Sarah Dias Azevedo

Universidade Federal Rural da Amazônia, Brasil

http://lattes.cnpq.br/7721203184014688

http://orcid.org/0000-0002-5105-1794

saaahazevedo@gmail.com

Lorena Fernanda Araújo Soares (iD)

Universidade Federal do Pará, Brasil

http://lattes.cnpq.br/3424684009064743

http://orcid.org/0000-0002-3757-2155

lorenaasoaares@gmail.com

Leandro Marques Torres

Universidade Federal Rural da Amazônia, Brasil

http://lattes.cnpq.br/2678860527695504

http://orcid.org/0000-0001-5976-6340

leandrotorres15@yahoo.com.br
Received: 02/01/2021

Approved: 27/01/2021
Referencing this:

AZEVEDO, S. D.; SOARES, L. F. A.; TORRES, L. M.. Temperatura de superfície e uso e cobertura do solo em municípios da região metropolitana de Belém/PA. Revista Ibero Americana de Ciências Ambientais, v.12, n.1, p.214-222, 2021. DOI:

http://doi.org/10.6008/CBPC2179-6858.2021.001.0018 


\section{INTRODUÇÃO}

A expansão demográfica no Brasil é relativamente recente e veio acompanhada de grandes transformações na sociedade. Seu início articula-se com um conjunto de mudanças estruturais na economia a partir da década de 30, mas somente em 1970 os dados censitários revelam uma população urbana superior à rural (BRITO et al., 2005). Essa concentração populacional dos centros urbanos favorece o processo acelerado de mudanças ambientais, em função das alterações nas coberturas das superfícies do solo (CALLEJAS, 2012).

De acordo com Monteiro (1976), o clima urbano resulta da combinação das características do sítio urbano com as formas de uso e ocupação da terra, condições geradoras de um clima inerente a cada região (TEIXEIRA et al., 2018). As formas de uso e cobertura do solo desordenadas resultam na intensa impermeabilização das cidades, ocupação gradativa de áreas ambientalmente frágeis, além de provocar a intensificação das ilhas de calor (RAMIRES et al., 2018).

De fato, o clima de uma região está conectado diretamente com o tipo de cobertura de sua superfície, visto sua importância fundamental na regulação na parcela de energia disponível para o processo de aquecimento da atmosfera e evapotranspiração (PAVÃO et al., 2015). Transformações na cobertura do solo influenciam inicialmente o albedo da superfície, tendo consequências sobre o balanço de radiação da superfície (CUNHA et al., 2013). A modificação da vegetação primaria também ocasiona modificações no padrão de distribuição de energia disponível. Uma maior disponibilidade de biomassa ocasiona um maior efeito termohidroregulador e consequentemente, um menor aquecimento. Logo, a energia disponível é utilizada sobretudo para o processo de evapotranspiração.

O geoprocessamento têm sido uma ferramenta primordial, com grandes avanços, para as etapas de levantamento e processamento de informações relacionadas a questões ambientais (PADILHA, 2016; GUTIERREZ et al., 2017). Inúmeros estudos vêm sendo desenvolvidos com a utilização de dados e técnicas de sensoriamento remoto orbital e suborbital na identificação de áreas de riscos, estudos geológicos, geomorfológicos, crescimento urbano, conforto térmico, uso e cobertura da terra, entre outros (COELHO et al., 2013). De tal modo, pesquisas com o uso da imagem termal diversas vêm sendo desenvolvidas, como exemplo a pesquisa realizada por Rao (1972), a qual o primeiro a evidenciar que é possível identificar áreas urbanas através da análise dados na faixa do infravermelho termal adquiridos por um satélite. Outros pesquisadores, como Fialho (2012), se utilizam de sistemas de sensoriamento remoto infravermelhos termais no estudo dos efeitos de ilha de calor e na obtenção de informação de temperatura da superfície de diversos materiais.

Nesse sentido, o estudo tem como objetivo avaliar as alterações de temperatura de superfície terrestre e no uso e cobertura do solo nos anos de 2001, 2008 e 2018 nos municípios de Belém e AnanindeuaPA, com uso de imagens dos satélites Landsat 5 e 8 . A justificativa desta pesquisa seria o incentivo à criação de propostas mitigadoras em políticas públicas, para atenuação da sensação térmica em ambientes urbanos confeccionando melhor qualidade de vida aos habitantes. 


\section{MATERIAIS E MÉTODOS}

A área de estudo do presente trabalho compreende os municípios de Belém e Ananindeua, parte da região metropolitana de Belém/Pará $(\mathrm{RMB})$, região norte do Brasil. Os municípios continuem um território de $1.059,458 \mathrm{~km}^{2}$ e $190,451 \mathrm{~km}^{2}$, respectivamente, com um total territorial de 1.250,031 km² (IBGE, 2018 ). Os municípios de Belém e Ananindeua, segundo dados do Anuário Estatístico do Pará, tem uma população de 2.011.298 de habitantes, o que equivale a 81\% da população da RMB (FAPESPA, 2019).

O município de Belém, possui uma população estimada de 14.857.32 habitantes em sua área de 1.059,458 km2, sendo o segundo município com maior número de habitantes da Região Norte do Brasil, perdendo apenas para Manaus com 2.182.76 (IBGE, 2019). A cidade de Belém está localizada nos pontos de latitude $01^{\circ} 27^{\prime} 22^{\prime \prime}$ Sul e longitude $48^{\circ} 30^{\prime} 14^{\prime \prime}$ Oeste (Figura 1).

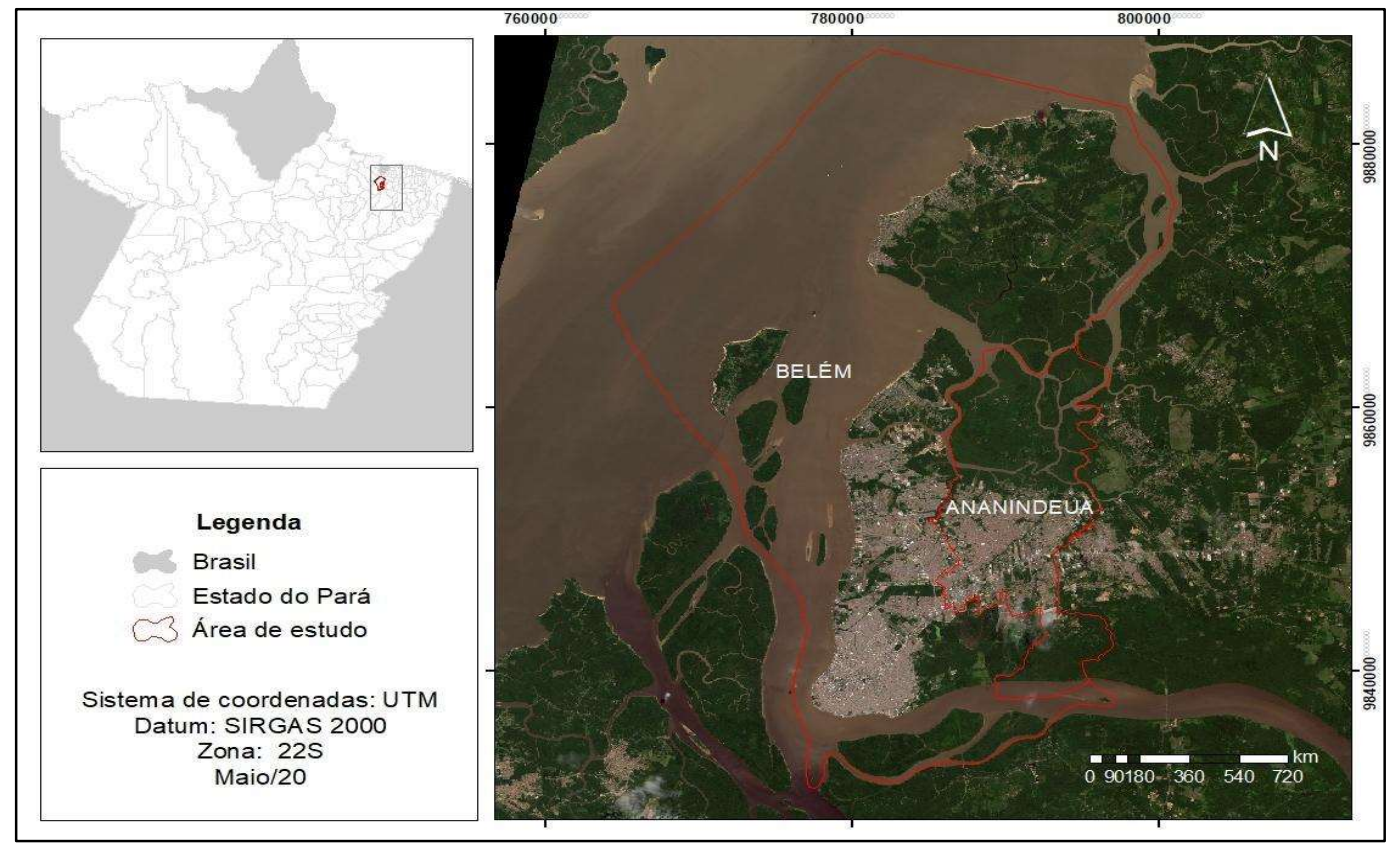

Figura 1: Mapa de localização dos municípios de Belém e Ananindeua/PA.

Localizado nas coordenadas de latitude $01^{\circ} 21^{\prime} 57^{\prime \prime}$ Sul e longitude $48^{\circ} 22^{\prime} 19^{\prime \prime}$ Oeste, o município de Ananindeua faz fronteira com o município de Belém e também sendo parte da região metropolitana, o segundo município mais populoso do estado e terceiro do Norte, com população estimada de 525.566 (Figura 1).

Para as análises foram confeccionados mapas de Uso e Cobertura do solo e de Temperatura da Superfície Terrestre (TST). O tratamento e análise dos dados das imagens em todas as etapas foram realizados pelo software QGis 2.18. Na geração do mapa temático foram utilizadas imagens dos satélites Landsat 5 e Landsat 8 sensores Thematic Mapper (TM) e resolução espacial de 30 metros.

Com o objetivo de realizar uma análise temporal das modificações decorrente do avanço da urbanização nos municípios estudados, foram estipuladas três datas em anos distintos. Assim, foram selecionadas imagens para os meses de agosto de 2001, junho de 2008 e julho de 2018. Na realização do processo de classificação do uso e cobertura do solo, foi efetuada a composição colorida das imagens utilizando as bandas 5/4/3 (Landsat 5) e 4/3/2 (Landsat 8). 
Para o mapeamento das classes de uso e cobertura do solo, empregou-se a interpretação visual de forma, textura, tonalidade/cor e comportamento espectral das unidades que compõe a paisagem. A classificação da imagem seguiu de forma supervisionada utilizando o algoritmo de Máxima Verossimilhança (Maxver). Foram coletadas amostras de treinamento das classes de uso e cobertura do solo referente à vegetação densa, vegetação secundária, áreas antropizadas e corpos d’água (Figura 2).

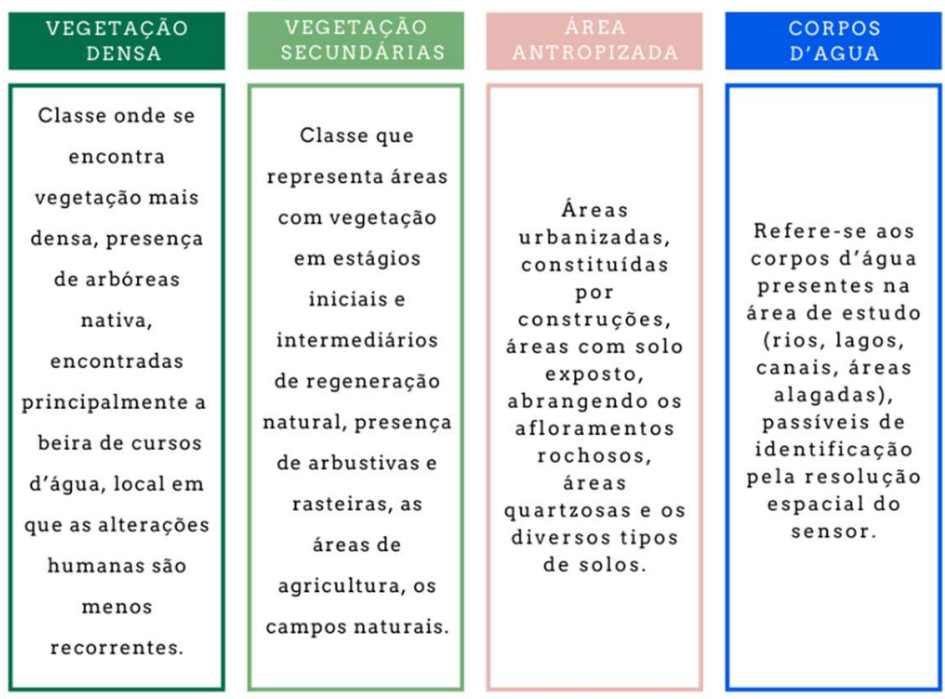

Figura 2: Descrição das classes de uso e cobertura do solo encontradas

Para investigação dos efeitos da urbanização dos municípios sobre a temperatura de superfície foi realizada a transformação das imagens raster em valores de TST pela utilização das bandas termais 6 e 10 dos satélites Landsat 5 e 8, respectivamente.

Inicialmente foi realizada a conversão dos níveis de cinza das bandas 6 e 10 em radiância espectral (TOA) através da equação 1 . As constantes térmicas foram adquiridas através arquivo de metadados das imagens (Tabela 1 e 2).

$$
L_{\lambda}=M_{L} * Q_{C a l}+A_{L}
$$

Tabela 1: Elementos e valores da fórmula de conversão para radiância extraídos do metadados da imagem do Landsat5, banda 6 e Landsat-8, banda 10 .

\begin{tabular}{|c|c|c|c|}
\hline Símbolo & Grandeza & $\begin{array}{l}\text { Valor } \\
\text { Landsat-5 }\end{array}$ & Landsat-8 \\
\hline$L_{\lambda}$ & Radiância espectral $\left(W \cdot m^{-2} \cdot s r . \mu m\right)$ & - & - \\
\hline$M_{L}$ & Fator multiplicativo de redimensionamento da banda & 0,055375 & 0,0003420 \\
\hline$A_{L}$ & Fator aditivo de redimensionamento da banda. & 1,18243 & 0,10000 \\
\hline$Q_{C a l}$ & Valor quantizado e calibrado do pixel em nível de cinza (DN) & Banda 6 & Banda 10 \\
\hline
\end{tabular}

Após a transformação dos valores em radiância da equação 1, aplicou-se a equação 2 com a finalidade de transformar os valores obtidos na primeira, em temperatura de valor em Kelvin, a qual será subtraída pelo seu valor absoluto $(273,15)$, gerando o raster de temperatura de superfície em graus Celsius $\left({ }^{\circ} \mathrm{C}\right)$.

$$
T_{s c}=\left(\frac{K_{2}}{\operatorname{In}\left(\frac{K_{1}}{L_{\lambda}}+1\right)}\right)-273.15
$$


Tabela 2: Elementos e valores da constante de calibração extraídos do metadados da imagem Landsat-5, banda 6 e Landsat-8, banda 10.

\begin{tabular}{cll}
\hline Símbolo & Grandeza & Valor utilizado \\
Landsat-5
\end{tabular}

\section{RESULTADOS E DISCUSSÃO}

Através da análise do mapeamento das classes de uso e ocupação do solo dos municípios Belém e Ananindeua foi possível observar que houve alteração ao longo dos anos (Figura 3). Verificou-se aumento de áreas antropizadas e diminuição de vegetação densa e secundária.

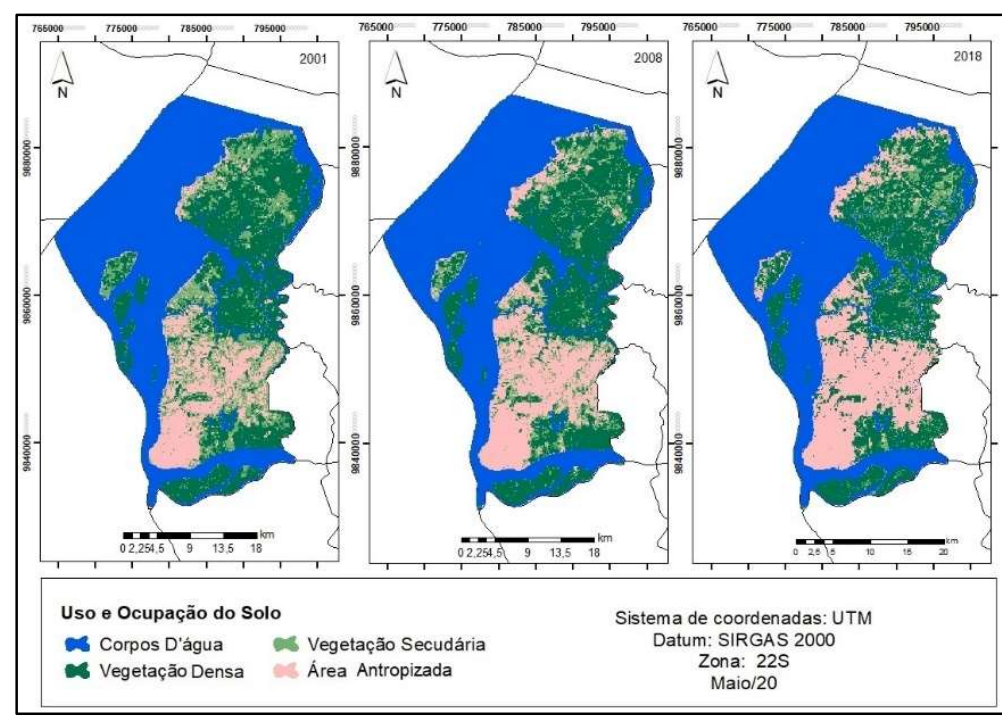

Figura 3: Mapa de uso e ocupação do solo dos municípios Belém e Ananindeua.

Em 2001, a classe vegetação densa correspondia a 27\% do solo, sendo a área com a segunda maior representatividade, perdendo apenas para os corpos d'água. Constatou-se que não ocorreu variação nessa classe dos anos de 2001 a 2008, havendo mudança significativa apenas no ano de 2018. No ano de 2018 ocorreu uma perda de $3 \%$ da vegetação densa nos municípios avaliados, isso representa $34,42 \mathrm{Km}^{2}$, essa perde pode ser visualizada principalmente na área da ilha de Mosqueiro (Tabela 3).

Tabela 3: Classes de uso e cobertura encontrados e uso respectivas áreas nos anos de 2001, 2008 e 2018.

\begin{tabular}{|c|c|c|c|c|c|c|}
\hline \multirow[t]{2}{*}{ Classes } & \multicolumn{2}{|l|}{2001} & \multicolumn{2}{|l|}{2008} & \multicolumn{2}{|l|}{2018} \\
\hline & $\mathrm{km}^{2}$ & $\%$ & $\mathbf{k m}^{2}$ & $\%$ & $\mathrm{~km}^{2}$ & $\%$ \\
\hline Corpos d'água & 610,68 & $49 \%$ & 610,67 & $49 \%$ & 610,68 & $49 \%$ \\
\hline $\begin{array}{l}\text { Vegetação } \\
\text { densa }\end{array}$ & 334,31 & $27 \%$ & 334,31 & $27 \%$ & 299,49 & $24 \%$ \\
\hline $\begin{array}{l}\text { Vegetação } \\
\text { secundária }\end{array}$ & 147,26 & $12 \%$ & 103,38 & $8 \%$ & 82,89 & $7 \%$ \\
\hline Antropizado & 161,19 & $13 \%$ & 205,08 & $16 \%$ & 260,37 & $21 \%$ \\
\hline
\end{tabular}

A ilha de mosqueiro localizada ao norte de Belém, apesar de deter uma grande área vegetada, vem sofrendo com o avanço das construções urbanas nas áreas próximas ao seu litoral, o que vem ocasionando a redução de suas áreas verdes (CORRÊA et al., 2015). Tal processo tende a se manter crescente em decorrência sobretudo à deficiência no planejamento urbano na ilha, em associado com o intenso apelo 
turístico da região devido grande extensão praiana e o baixo valor imobiliário das terras, assim como ao fato de ser relativamente proximidade do centro urbano de Belém-PA (CABRAL et al., 2015). De fato, os autores Oliveira et al. (2018) ao avaliarem as modificações paisagísticas da ilha dos anos de 2010 a 2015 verificaram que nos anos avaliados ocorreu uma perda de $10.8 \%\left(19,28 \mathrm{~km}^{2}\right)$ da cobertura vegetal em contrapartida ao avanço de áreas urbanizadas e de solo exposto.

Identificou-se que a maior parte da vegetação densa observada na região sul das cidades são pertencentes a unidades de conservação, como o Parque Estadual do Utinga (PEUt), a Área de Proteção Ambiental (APA) da RMB e a Reserva da Vida Silvestre Metrópole da Amazônia. Para além disso, nota-se que as áreas com grande parte da cobertura vegetal dos municípios encontram-se na região conhecida como insular, área onde ficam localizadas as ilhas. O município de Ananindeua conta com nove ilhas, sendo uma área pouco habitada, mas que devido ao desmatamento e outras atividades antrópicas vem tendo um crescente aumento de áreas com floresta secundária em vários estágios de desenvolvimento (FERREIRA et al., 2009).

Quanto a área do Parque Estadual do Utinga (PEUt), apesar da grande presença de cobertura vegetal densa, estudos realizados na área demostram o Parque vem sofrendo com a perda da vegetação com o avanço dos anos. Gutierrez et al. (2017) avaliaram o uso e cobertura do solo da APA Belém nos anos de 1984 a 2015 que verificou uma diminuição de 4,8\% da área de vegetação primaria, equivalente a 2,24 Km². Tal fato decorre principalmente pela ocupação humana dos mananciais que na pesquisa citava teve um aumento de $110 \%\left(19,5 \mathrm{Km}^{2}\right)$. Santos et al. (2015) evidenciam que a Área de Proteção Ambiental da RMB, que por lei deveria ser ocupada por vegetação nativa, está cada vez mais sendo ocupada por áreas urbanas, deixando assim de realizar as suas funções ambientais para a manutenção do equilíbrio ambiental.

Em relação a classe vegetação secundaria, observou-se que de 2001 a 2018 ocorreu uma perda de $44 \%$ dessa classe, o que equivale a $64,37 \mathrm{Km}^{2}$. No Gráfico 1 verifica-se a dinâmica temporal das áreas das classes de coberturas do solo no período estudado, o que permite visualizar a diminuição da classe vegetação secundaria acompanhada do aumento da classe antropizado, o fato pode ser motivado pelo avanço da horizontalização das cidades em busca de novas áreas para moradia, especialmente em localizações mais distantes do centro. Tal relação também foi visualizada por Costa et al. (2016) que avaliou a mesma área, porém no período de 1884 a 2015.

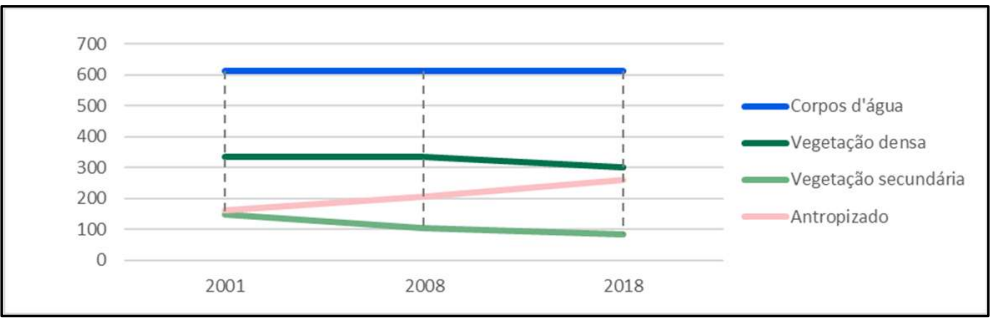

Gráfico 1: Dinâmica temporal das áreas das classes de uso e cobertura do solo.

Quanto a classe área antropizada, observou-se um aumento de $62 \%\left(99,18 \mathrm{Km}^{2}\right)$ nos anos avaliados, foi a classe onde ocorreu a maior evolução de área. Tal crescimento traz certas preocupações visto que 
muitas vezes ocorre sem o devido planejamento, vindo acompanhados de uma série de problemas econômicos, sociais e ambientais. Alves et al. (2019), citam algumas consequências ambientais do processo expansão urbana como o crescimento significativo de áreas impermeabilizadas, o que ocasiona a diminuição do índice de precipitação, reduzindo a infiltração e, por conseguinte, aumentado o escoamento superficial, podendo ocasionar transtornos como enchentes. Outro problema apontado por Sousa et al. (2012) é a questão do conformo termino, no seu estudo os autores verificaram que pouca ou nenhuma cobertura vegetal em áreas urbanas, registraram temperaturas superficiais mais altas.

Para a temperatura dos municípios em estudo observou-se que na região norte no ano de 2001, a temperatura era de no máximo $23^{\circ} \mathrm{C}$, no entanto, no ano de 2018 apresentou valores superiores, variando de $20^{\circ} \mathrm{C}$ a $26^{\circ} \mathrm{C}$ (Figura 4). Esta mudança de temperatura pode ser explicada devido a diminuição de áreas com vegetação densa e secundária e aumento das áreas antropizadas na região.

Resultados semelhantes foram encontrados por Santos (2019) em seu estudo, à medida que a proporção de cobertura vegetal reduz os valores e as amplitudes da temperatura de superfície tendem inversamente, a se elevar. Ainda de acordo com o mesmo autor esse resultado indicou um comprometimento da qualidade térmica da cidade, predominantemente nas regiões onde a presença de vegetação é mais reduzida.

$\mathrm{Na}$ região central, no ano de 2001, as temperaturas variaram entre 20 e $26^{\circ} \mathrm{C}$ (Figura 4) sendo estas consideradas aceitáveis. Para o ano de 2008, observou-se valores bem superiores aos verificados 7 anos antes, com variação da temperatura de $23^{\circ} \mathrm{C}$ a $29^{\circ} \mathrm{C}$ e em alguns pontos superior a $29^{\circ} \mathrm{C}$, semelhante ao observado no ano de 2018. Em relação a região sul, também ocorreu aumento da temperatura ao longo dos anos, principalmente nas áreas antropizadas com pouca vegetação.

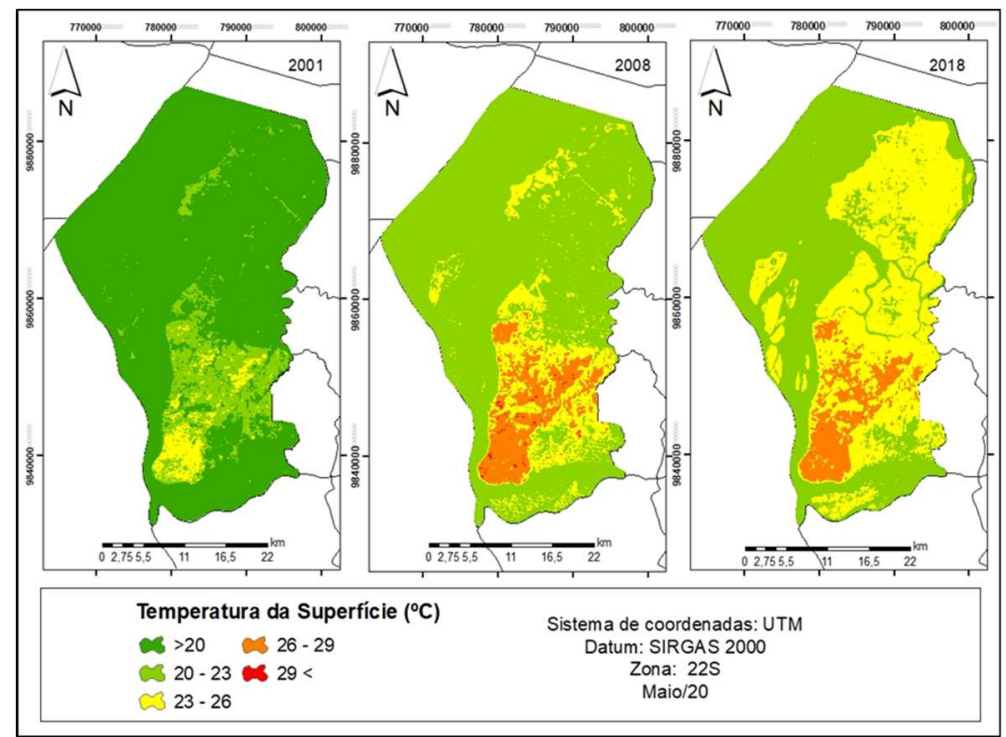

Figura 4: Temperatura da superfície dos municípios de Belém e Ananindeua.

Os maiores valores de temperatura da superfície verificados em áreas de campos ou em áreas modificadas que apresentam baixa densidade de vegetação, ocorre devido a energia disponível ao ambiente ser utilizada prioritariamente para aquecimento do solo e do ar adjacente à superfície. Por outro lado, na floresta, devido à sua maior densidade de vegetação, a maior parte da energia disponível ao ambiente é 
distribuída para o processo de evapotranspiração, resfriando a superfície vegetada (BIUDES et al., 2009; LEAL, 2012; PAVÃO et al., 2015).

Além disso, grande parte da radiação solar incidente penetra no interior da floresta antes de ser refletida, resultando em uma acentuada captura de radiação solar e, consequentemente, em baixa reflexão. Tal fato, explica a diminuição gradativa da temperatura da superfície na medida em que a vegetação se torna mais densa (LEITÃO et al., 2002; PAVÃO et al., 2015).

\section{CONCLUSÕES}

De acordo com os resultados deste trabalho, verificou-se que com o passar dos anos correram temperaturas mais elevadas, acompanhadas pelo aumento das áreas antropizadas e diminuição de áreas vegetadas, ocasionando um desconforto térmico para a população, mostrando a importância da vegetação na amenização da temperatura em uma determinada área.

De fato, o aumento da urbanização nesses municípios metropolitanos vem se intensificando ao decorrer do tempo e invadido novas áreas, o que ocasiona um desequilíbrio ambiental cada vez maior nessas regiões. Assim, as ferramentas de geoprocessamento se mostram excelentes para o diagnóstico e a tomada de decisão no monitoramento da qualidade ambiental e do planejamento urbano da região.

\section{REFERÊNCIAS}

ALVES, H. R. C.; MELO, A. J. S.; NETO, A. P. C.; COSTA, J. A.. Uso e Cobertura do Solo da Bacia Hidrográfica do Rio Benfica-PA. Anuário do Instituto de Geociências, v.42, n.2, p.333-340, 2019

BIUDES, M. S.; CAMPELO JUNIOR, J. H.; NOGUEIRA, J. S.; SANCHES, L.. Estimativa do balanço de energia em cambarazal e pastagem no norte do Pantanal pelo método de razão de Bowen. Revista Brasileira de Meteorologia, v.24, n.2, p.135-143, 2009. DOI: https://doi.org/10.1590/S0102-77862009000200003

BRITO, F.; SOUZA, J.. Expansão urbana nas grandes metrópoles: o significado das migrações intrametropolitanas e da mobilidade pendular na reprodução da pobreza. São Paulo em Perspectiva, v.19, n.4, p.48-63, 2005. DOI: https://doi.org/10.1590/S0102-88392005000400003

CABRAL, E. R.; DIAS, J. S.; GOMES, S. C.. Gestão ambiental em espaços de lazer e turismo: as praias urbanas da Amazônia brasileira. Rosa dos Ventos, v.7, n.2, p.269-287, 2015.

CALLEJAS, I. J. A.. Avaliação temporal do balanço de energia em ambientes urbanos na cidade de Cuiabá/MT. Tese (Doutorado em Física Ambiental) - Universidade Federal de Mato Grosso, Cuiabá, 2012.

COELHO, A. L. N.; CORREA, W. S. C.. Temperatura de Superfície Celsius do Sensor TIRS/Landsat-8: metodologia e aplicações. Revista Geográfica Acadêmica, v.7, n.1, p.31-45, 2013.

CORRÊA, R. S.; SILVA, R. V. B.. Ocupação urbana e degradação ambiental: ocupação, simbolismo e cidadania ambiental no bairro do Paraíso, Mosqueiro/PA. Revista
Perspectivas do Desenvolvimento: um enfoque multidimensional, v.3, n.4, p.1-25, 2015.

COSTA, A. M. S.; BEZERRA, P. E. S.; OLIVEIRA, R. S.. Análise da temperatura da superfície terrestre associada à dinâmica do uso e ocupação do solo nos municípios de Belém e Ananindeua, Pará, Brasil. In: SIMPÓSIO DE GEOTECNOLOGIAS NO PANTANAL, 6. Anais. Cuiabá: Embrapa Informática Agropecuária/INPE, 2016.

CUNHA, A. P. M. A.; ALVALA, R. C. S.; OLIVEIRA, G. S.. Impactos das mudanças de cobertura vegetal nos processos de superfície na região semiárida do Brasil. Revista Brasileira de Meteorologia, v.28, n.2, p.139152. 2013. DOI: https://doi.org/10.1590/S0102$\underline{77862013000200003}$

FAPESPA. Fundação Amazônia Paraense de Amparo à Pesquisa. Anuário Estatístico do Pará. 4 ed. Belém: FAPESPA, 2019.

FIALHO, E. S.. Estudos climáticos em sítios urbanos e rurais. In: SILVA, C. A.; FIALHO E. S.. Concepções e Ensaios da Climatologia Geográfica e-book. Grande Dourados: UFGD, 2012. p.83-112.

GUTIERREZ, C. B. B.; RIBEIRO, H. M. C.; MORALES, G. P.; GUTIERREZ, D. M. G.; SANTOS, L. S.; PAULA, M. T.. Análise espaço-temporal do uso e cobertura do solo no interior da APA Belém e correlação com os parâmetros de água dos seus mananciais. Revista Brasileira de Geografia Física, v.10, n.1, p.521-534. 2017.

DOI: https://doi.org/10.5935/1984-2295.20170033

FERREIRA, H. A.; SANTOS, O. C. O.. A ocupação, a cobertura 
vegetal e as chuvas no município de Ananindeua. In: SIMPÓSIO BRASILEIRO DE GEOGRAFIA FÍSICA APLICADA, 11. Anais. Viçosa: Universidade Federal de Viçosa, 2009.

IBGE. Instituto Brasileiro de Geografia e Estatística. Área territorial brasileira. Rio de Janeiro: IBGE, 2018.

IBGE. Instituto Brasileiro de Geografia e Estatística. Estimativas da população residente para os municípios e para as unidades da federação com data de referência em 10 de julho de 2019. Rio de Janeiro: IBGE, 2019.

LEAL, L.. A influência da vegetação no clima urbano da cidade de Curitiba/PR. Tese (Doutorado em Engenharia Florestal) - Universidade Federal do Paraná, Curitiba, 2012.

LEITÃO, M. M. V. B. R.; SANTOS, J. M.; OLIVEIRA, G. M.. Estimativas do albedo em três ecossistemas da floresta amazônica. Revista Brasileira de Engenharia Agrícola e Ambiental, v.6, n.2, p.256-261. 2002. DOI: https://doi.org/10.1590/S1415-43662002000200013

OLIVEIRA, T. T. G. T.; BEZERRA, P. E. S.; PONTES, A. N.; MARTINS, A. C. C. T.. Modificações paisagísticas e implicações térmicas no distrito administrativo de Belém, Pará. Revista Verde de Agroecologia e Desenvolvimento Sustentável, v.13, n.3, p.404-411, 2018.

PADILHA, R.; PORTUGAL, J. L.; SANTOS, A. V.; PEREIRA, S. V.; CARMO, T. V. B.. Proposição de Modelo de Corredores Ecológicos com Base no Sistema de Informações Geográficas na Região de Suape, Pernambuco, Brasil. Revista Brasileira de Geografia Física, v.9, n.1, p.79-90. 2016. DOI: https://doi.org/10.26848/rbgf.v9.1.p079-090

PAVÃO, V. M.; QUERINO, C. A. S.; BENEDITTI, C. A.; PAVÃO L. L.; QUERINO, J. K. A. S.; MACHADO, N. G.; BIUDES, M. S. Temperatura e albedo da superfície por imagens TM Landsat
5 em diferentes usos do solo no sudoeste da Amazônia brasileira. Revista Brasileira de Climatologia, v.16, p.169183, 2015. DOI:

http://dx.doi.org/10.5380/abclima.v16i0.40128

RAMIRES, J. Z. S. R.; MELLO-THÉRY, N. A.. Uso e ocupação do solo em São Paulo, alterações climáticas e os riscos ambientais contemporâneos. Confins, n.34, 2018. DOI: https://doi.org/10.4000/confins.12779

SANTOS, L. S.; GUTIERREZ, C. B. B.; DIAS, N. M.; PONTES, A. N.. Análise Espacial na Gestão de Recursos Hídricos: Bacia Hidrográfica do Rio Uriboca, Belém, Pará. Enciclopédia Biosfera, v.11, n.22, p.161-172, 2015. DOI: http://dx.doi.org/10.18677/Enciclopedia Biosfera 201507 8

SANTOS, R. A.. Cobertura vegetal e a temperatura de superfície no meio intraurbano: um estudo em Salvador. Dissertação (Mestrado em Meio Ambiente, Água e Saneamento). Universidade Federal da Bahia, Salvador, 2019.

SOUSA, S. B.; FERREIRA JÚNIOR, L. G.. Relação entre temperatura de superfície terrestre, índices espectrais e classes de cobertura da terra no município de Goiânia (GO). Raega: O Espaço Geográfico em Análise, v.26, 2012. DOI: http://dx.doi.org/10.5380/raega.v26i0.30151

RAO, P. K.. Remote sensing of urban 'heat islands' from an environmental satellite. Bulletin of the American Meteorological Society, v.53, p.647-648, 1972.

TEIXEIRA, D. C. F.; AMORIM, M.. O estudo da ilha de calor em cidade de pequeno porte: algumas contribuições. Sociedade \& Natureza, v.30, n.2, p.186-209, 2018. DOI: https://doi.org/10.14393/SN-v30n2-2018-9

A CBPC - Companhia Brasileira de Produção Científica (CNPJ: 11.221.422/0001-03) detém os direitos materiais desta publicação. Os direitos referem-se à publicação do trabalho em qualquer parte do mundo, incluindo os direitos às renovações, expansões e disseminações da contribuição, bem como outros direitos subsidiários. Todos os trabalhos publicados eletronicamente poderão posteriormente ser publicados em coletâneas impressas sob coordenação da Sustenere Publishing, da Companhia Brasileira de Produção Científica e seus parceiros autorizados. Os (as) autores (as) preservam os direitos autorais, mas não têm permissão para a publicação da contribuição em outro meio, impresso ou digital, em português ou em tradução. 